DOI: 10.20472/IAC.2017.33.035

\author{
CHAN-WOO KIM \\ Kyungpook National University, Korea, Republic of \\ CHANG-KYO SUH \\ Kyungpook National University, Korea, Republic of
}

\title{
FACTORS AFFECTING THE INTENTION TO USE THE INTELLIGENT PERSONAL ASSISTANT
}

\begin{abstract}
:
An intelligent personal assistant (IPA) is a software agent that assists people to perform basic tasks or services for an individual, usually providing information via natural language. In spite of the versatile capabilities of the IPA to answer a user's simple information-based queries such as the weather and driving directions, the limited actual usage rates for the IPA services are reported so far.

In this research, to evaluate the factors affecting the intention to use the IPA we develop the empirical model based on the technology acceptance model (TAM), innovation diffusion theory, and IS success model. Then, we collect the questionnaires from the actual users of the IPAs. Finally, the structural equation model validates the causal relationship between the constructs of the model. The major findings and suggestion for further research will be discussed in the conference in details.
\end{abstract}

\section{Keywords:}

IPA, TAM, Innovation Diffusion Theory, IS Success Model

JEL Classification: M15, M10 